\title{
Melanin-based coloration predicts aggressiveness and boldness in captive eastern Hermann's tortoises
}

\author{
Alia Mafli ${ }^{\mathrm{a}}$, Kazumasa Wakamatsu ${ }^{\mathrm{b}, 1}$, Alexandre Roulin ${ }^{\mathrm{a}, *}$

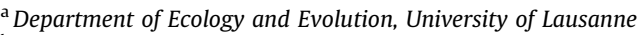 \\ ${ }^{\mathrm{b}}$ School of Health Sciences, Fujita Health University
}

\section{A R T I C L E I N F O}

Article history:

Received 22 June 2010

Initial acceptance 20 September 2010

Final acceptance 25 January 2011

Available online $\mathrm{xxx}$

MS. number: 10-00446R

\section{Keywords:}

activity

aggressiveness

behavioural syndrome

boldness

coloration

Eurotestudo boettgeri

exploration

melanin

personality

tortoise
Although body coloration is often used in social interactions, few studies have tested whether it is linked to a suite of behavioural traits. We examined whether among captive adult male eastern Hermann's tortoises, Eurotestudo boettgeri, behavioural patterns covary with eumelanic coloration of the shell. Dark eumelanic males were more aggressive in male-male confrontations and bolder towards humans. These relationships were independent of body size and ambient temperature. Activity level and exploration were not significantly associated with coloration. We conclude that, at least in captivity, melanic shell coloration predicts agonistic behaviour towards conspecifics and fearfulness towards humans (i.e. boldness).

2011 The Association for the Study of Animal Behaviour. Published by Elsevier Ltd.
Behaviour is regulated by genetic and environmental factors as well as experience (Sih et al. 2004). Recently, the melanocortin system has been proposed to generate correlations between behavioural patterns, the so-called behavioural syndromes. Melanocortin hormones bind to five melanocortin receptors, each one being associated with different physiological and behavioural functions. The melanocortin system is implicated in melanogenesis, raising the possibility that melanin-based coloration may covary with these physiological and behavioural functions (Ducrest et al. 2008; Vercken \& Clobert 2008a). Indeed, a review of the empirical literature in vertebrates revealed that darker eumelanic animals are often more aggressive, sexually more active and more resistant to various sources of stress than lighter coloured animals (Ducrest et al. 2008). It is thus not surprising that melanin-based colour traits is a criterion in mate choice and thus associated with social dominance (Jawor \& Breitwisch 2003). While these latter

\footnotetext{
* Correspondence: A. Roulin, Department of Ecology and Evolution, University of Lausanne, 1015 Lausanne, Switzerland.

E-mail address: Alexandre.Roulin@unil.ch (A. Roulin).

${ }^{1} \mathrm{~K}$. Wakamatsu is at the School of Health Sciences, Fujita Health University, Toyoake, Aichi 470-1192, Japan.
}

phenotypic associations have been verified in various species of birds, mammals, amphibians and fish, few studies have been performed in reptiles (but see Auffenberg 1965; Lardie 1983; Kramer 1986; Vercken \& Clobert 2008b), although similar proximate mechanisms regulate behaviour in this taxon (Cooper \& Greenberg 1992). These animals are particularly interesting because melanin plays an important role in thermoregulation, with the dark melanic carapace facilitating heating and protecting tissues from damaging ultraviolet radiation (Porter \& Norris 1969). Furthermore, at a given solar radiation, darker individuals show lower skin reflectance, heat up more rapidly and can maintain their optimal body temperature better than lighter coloured individuals at low temperatures. Consequently, darker individuals may have a higher fitness in colder and higher altitudinal regions than lighter coloured individuals (Trullas et al. 2007).

In the present study, we investigated whether the pronounced eumelanin-based colour variation is associated with distinct behavioural traits in captive adult male Hermann's tortoises, Eurotestudo boettgeri (Lapparent de Broin et al. 2006), that is, aggressiveness between males, fearfulness towards humans (i.e. shyness-boldness behaviour), activity and exploration-avoidance. We did not consider sociality because tortoises usually live alone 
and meet randomly or during the breeding season to mate and defend their territory (Vetter 2006). Our aim was to examine whether these behavioural traits are correlated with eumelanic (i.e. black) pigmentation of the hidden and visible parts of the shell (i.e. plastron and carapace, respectively).

\section{METHODS}

\section{Study Organism}

The eastern Hermann's tortoise is native to the Balkans and Greece and is one of Europe's most common tortoise species bred in captivity. In the wild, E. boettgeri is mainly herbivorous but also eats fruits, mushrooms and small invertebrates. In captivity, sexual maturity is reached at $8-10$ years in males. The dark shell pigmentation usually covers less than $50 \%$ of each scute, and the rest is yellowish to brownish. A high variation in melanin-based coloration is found among individuals between and within populations as well as within a single clutch (Willemsen \& Hailey 1999; Vetter 2006).

\section{Study Site and Outdoor Maintenance}

Experiments were performed in the outdoor animal research facility buildings of the University of Lausanne. From April to May 2009 we assessed behaviour in 25 adult males (aged $>15$ years) lent by five private breeders. All tortoises were previously kept outside by their breeders and fed ad libitum with various plants regularly distributed or already present in their enclosure. Breeders avoid inbreeding by buying new males, implying that males used in the present study were probably unrelated. Because most animals were quite old (the Hermann's tortoise can live over 80 years), we do not know whether some of them were caught in the wild a long time ago. On their arrival at the university we measured body mass, length, width and height of the carapace. To obtain an index of body size we extracted the first component of a principal components analysis including these four measurements. The first component explained $72.5 \%$ of the variation in body size (eigenvector for body mass $=0.56$, length 0.30 , width 0.56 and height 0.53 ).

Before starting any experiment, tortoises were acclimatized to their new environment over 2 weeks. Using nail polish, we wrote an identifiable number on their backs to recognize them over the course of the study. Tortoises were kept individually in four pairs of wire-fencing enclosures, each one being split into four compartments of roughly $4 \mathrm{~m}^{2}$. The ground was naturally covered with edible plants and we also provided ad libitum other plants favoured by tortoises (dandelion, clover, plantain). Experiments were carried out in another enclosure of $4 \mathrm{~m}^{2}$. This site was not under shade and hence benefited from sunshine, which is important for poikilotherms. Additionally, shelters and drinking bowls were available. The enclosures were checked every day to remove faeces and to provide fresh water. In the enclosure dedicated to experiments, we also regularly cleared the ground of faeces and urine tracks after each trial to avoid olfactory marks, which can influence tortoise behaviour. This was easy because we put sand on the ground to facilitate cleaning. Any remaining traces of urine should not have biased our results in any way because the order in which we tested tortoises was not correlated with their melanic coloration (Pearson correlation: $P>0.54$ ). Over their stay of $34.4 \pm 0.6$ days (mean \pm SE; range $32-39)$ at the university, tortoises gained on average $7.2 \pm 1.1 \mathrm{~g}$ (mean body mass $=856 \pm 67 \mathrm{~g}$; paired $t$ test: $t_{23}=6.47, P<0.0001$ ).

\section{Assessment of Shell Coloration}

To measure shell coloration on the 38 scutes of the carapace and the 12 scutes of the plastron, six pictures of each tortoise were taken from the top, the bottom, both sides, the front and the back. The tortoises were held in a black box with two upper fluorescent lights and a camera was inserted in the top of the box with a hole for the zoom lens. Each picture was then analysed with the software ImageJ (Abramoff et al. 2004) to measure the percentage of the surface of each scute covered by dark coloration. We calculated a mean value across all scutes for the plastron and then for the carapace. Dark coloration on the plastron was correlated with dark coloration on the carapace (Pearson correlation: $r_{23}=0.55$, $P=0.004)$. Because this correlation was not very strong, we decided to carry out statistical analyses using coloration of both the carapace and plastron rather than with a mean value.

\section{Assessment of Aggressiveness Towards Conspecifics}

Adult males are aggressive at the end of spring, an important period for courtship and breeding. They engage in fights among themselves and show various tactics to defeat their opponent such as biting, ramming and knocking over other males (Vetter 2006). To measure the degree of aggressiveness, pairs of males were placed in an enclosure of $4 \mathrm{~m}^{2}$ dedicated to experiments for 6 days (3, 4, 6, 7, 8 and 9 June 2009). Outside the period when aggressiveness was studied, males were always kept separate in their enclosure to avoid any superfluous fights or injuries and also to prevent the establishment of any hierarchy or biased behaviour that could influence the outcome of the confrontation during the tests. Each of the 25 males was challenged in pairwise contests giving a total of 300 fights. For every confrontation we recorded the amount of time each male took before initiating a fight, whether it bit or rammed its opponent, which of the two individuals started the confrontation, gave up the fight (i.e. fleeing at the end of the fight or no longer retaliating against its opponent) and won the fight. At the end of a contest, the winning male often tried to climb on the back of the defeated male and remained aggressive until the latter had left its territory. We ended a confrontation if the defeated male was trying to escape from its opponent, if both males failed to fight or if the two males were equally strong (i.e. biting and/or ramming very frequently and at a similar frequency) and could be hurt if the fight lasted too long. Each fight lasted between 1 and 13 min (mean $\pm \mathrm{SE}=2.8 \pm 0.1$ ). After every fight, each male was returned to its own enclosure. For each individual we calculated a mean value over the 24 fights. We derived an index of aggressiveness by extracting the first component of a principal components analysis. The first component explained $64.5 \%$ of the variation with the eigenvector for the time needed to start a fight being 0.10 , the rate of biting 0.46 , the rate of ramming 0.35 , the rate of initiating a fight 0.47 , the percentage of giving up fights -0.44 and the percentage of fights that tortoises won 0.49 . More details on this experiment can be found in Table 1.

\section{Assessment of Fearfulness Towards Humans}

To investigate the extent to which tortoises adopt a fearful behaviour towards humans, we confronted them with a food-predator dilemma. One of us held an appetizing piece of apple at a distance of $50 \mathrm{~cm}$ from the nose of each tortoise. Tortoises were not used to being hand fed, but during the acclimatization period they were regularly fed with apple slices (but not by hand) to accustom them to eating this fruit. When the fruit was presented by hand the immediate reaction of each tortoise was recorded. Shy individuals were assigned the score 1 (i.e. retracted head and forelegs into the shell), intermediately shy individuals scored 2 (i.e. retracted the head only) and bold individuals scored 3 (i.e. did not retract). We also measured the amount of time the tortoises took before moving towards the hand $(\log +1$ transformed to normalize the data distribution), the time taken to begin eating (log +1 transformed) 
Table 1

Time schedule for the assessment of aggressiveness towards conspecifics in male eastern Hermann's tortoise

\begin{tabular}{|c|c|c|c|c|c|c|}
\hline & \multicolumn{6}{|c|}{ Date when aggressive behaviour was assessed } \\
\hline & 3 June & 4 June & 6 June & 7 June & 8 June & 9 June \\
\hline Number of fights & 30 & 16 & 50 & 76 & 78 & 50 \\
\hline $\begin{array}{l}\text { Mean number } \pm \text { SD of fights } \\
\text { per individual }\end{array}$ & $2.4 \pm 0.9(1-4)$ & $1.3 \pm 1.6(0-8)$ & $4.0 \pm 0.8(2-5)$ & $6.1 \pm 1.0(4-8)$ & $6.2 \pm 1.4(0-7)$ & $4.0 \pm 0.7(2-6)$ \\
\hline $\begin{array}{l}\text { Mean time span } \pm \text { SD between two } \\
\text { fights (min) }\end{array}$ & $3.3 \pm 1.7(2-11)$ & $3.6 \pm 1.2(2-6)$ & $2.8 \pm 0.8(2-4)$ & $2.7 \pm 1.8(1-13)$ & $2.6 \pm 1.1(2-8)$ & $2.5 \pm 1.2(1-9)$ \\
\hline $\begin{array}{l}\text { Mean time span } \pm \text { SD between } \\
\text { two fights for the same } \\
\text { individual ( } \mathrm{min} \text { ) }\end{array}$ & $40.4 \pm 17.6(12-86)$ & $18.8 \pm 14.1(3-45)$ & $32.9 \pm 11.2(17-109)$ & $35.4 \pm 20.4(6-155)$ & $31.1 \pm 8.2(9-66)$ & $30.3 \pm 14.7(3-101)$ \\
\hline
\end{tabular}

Ranges are given in parentheses.

and the duration of eating. Three trials were performed on 5, 10 and 12 June 2009 with, for each individual, an interval of 2-5 days between two successive tests (mean $\pm \mathrm{SE}=3.5 \pm 0.2$ days). A boldness index was obtained from a principal components analysis. The first component explained $36.8 \%$ of the variation with the eigenvector for the reaction to a hand presenting food being -0.68 , the time to reach the hand 0.63 , the time before starting to eat 0.34 and amount of time feeding -0.17 . Higher values of this index thus indicate that tortoises are shy. More details on this experiment can be found in Table 2.

\section{Assessment of Exploration Behaviour}

When left in a new environment, tortoises often explore it (Vetter 2006; Schilliger 2007). Because they have a good perception of colours, with cone pigments absorbing red, green and blue light, and can see ultraviolet (Cooper \& Greenberg 1992; Ventura et al. 2001), we used three red, yellow and green pots $15 \mathrm{~cm}$ high placed in a circle of $50 \mathrm{~cm}$ from each other in an enclosure. The position of each pot was randomly changed after each trial. Adult males were placed at a central point $50 \mathrm{~cm}$ from each pot. The time each tortoise took to move $(8.0 \pm 1.1 \mathrm{~s})$ and to visit pots (yellow: $43.1 \pm 5.9$ s; green: $42.9 \pm 7.9 \mathrm{~s}$; red: $47.7 \pm 8.3 \mathrm{~s}$ ) was measured as well as the number of times each pot was inspected. For each male, three trials were carried out on the 13, 15 and 20 June 2009, and mean values were calculated. An exploration index was obtained from a principal components analysis with the first component explaining $37.2 \%$ of the variation. The eigenvectors for the time taken before exploring were 0.38 , time to visit the first pot 0.64 and the total number of times pots were visited -0.67 .

\section{Assessment of Activity Level}

Tortoises were put alone in an experimental enclosure of $4 \mathrm{~m}^{2}$ and for $10 \mathrm{~min}$ we measured the total duration of activity. This was done on the 11, 14 and 16 June 2009, and a mean value was calculated. Tortoises were considered active if moving in the enclosure, eating or inspecting the ground. Each tortoise had already experienced this enclosure when we measured the other behavioural traits, and hence this environment was not novel. As for exploration behaviour, each trial lasted $10 \mathrm{~min}$.

\section{Statistical Procedure}

Statistical analyses were computed with the JMP package (Sall \& Lehman 1996). We considered ambient temperature measured during each test because, in poikilothermic animals, the activity levels are temperature dependent. Repeatabilities \pm SE were computed following Lessells \& Boag (1987). Tortoises lent by the five breeders did not differ with respect to coloration, behavioural traits and the index of body size (one-way ANOVAs: $P>0.18$ ). All statistical analyses are two tailed and $P$ values smaller than 0.05 are considered significant. Means are quoted $\pm \mathrm{SE}$.

\section{Ethical Note}

The experiments appeared not to be detrimental to tortoises since individuals gained weight during their stay at the university. During the fights no tortoise was hurt because we quickly separated the most violent individuals. Furthermore, the morphology of tortoises (robust shell and larger scutes on the forelegs) is well adapted to protect them from the attacks of conspecifics. The study was approved by the veterinary service of Canton de Vaud.

\section{RESULTS}

\section{Repeatability and Covariation Between Behavioural Traits}

Across 24 fights the index of aggressiveness was significantly repeatable within individuals $\left(r=0.89 \pm 0.02, \quad F_{24.531}=24.91\right.$, $P<0.0001)$. The indexes of boldness and activity level were also significantly repeatable $\left(r=0.54 \pm 0.05, F_{24,50}=4.54, P<0.0001\right.$; $\left.r=0.84 \pm 0.02, F_{24,50}=16.70, P<0.0001\right)$ but that for exploration was not $\left(F_{24,50}=1.42, P=0.15\right)$. The different behavioural traits were not correlated with each other (Pearson correlations: $P>0.20$ ).

\section{Coloration, Body Size and Body Mass Gain}

The index of body size was not associated with melanin-based coloration of the carapace and plastron (multiple regression analysis: $P>0.23$ ). A similar finding applies to the body mass gain over the stay at the university $(P>0.33)$.

Table 2

Time schedule for the assessment of fearfulness towards humans in male eastern Hermann's tortoise

\begin{tabular}{|c|c|c|c|}
\hline & \multicolumn{3}{|c|}{ Date when fearfulness towards humans was assessed } \\
\hline & 5 June & 10 June & 12 June \\
\hline Number of experiments & 25 & 25 & 25 \\
\hline Mean time span \pm SD between two experiments (min) & $2.2 \pm 1.7(1-5)$ & $1.6 \pm 0.8(1-4)$ & $1.9 \pm 0.9(1-5)$ \\
\hline Mean time duration \pm SD of an experiment $(\min )$ & $8.9 \pm 2.6(4-14)$ & $9.7 \pm 3.1(3-14)$ & $8.5 \pm 4.0(2-18)$ \\
\hline
\end{tabular}

Ranges are given in parentheses. 


\section{Coloration and Behaviour}

In multiple regression analyses with behavioural measures as dependent variables in separate models, and eumelanin-based coloration of the carapace and plastron, mean temperature and the index of body size as four independent variables, coloration was not associated with activity level or with the index of exploration (after eliminating the least significant variables one after the other all Ps $>0.09$ ). The index of aggressiveness was positively associated with coloration of the carapace $\left(F_{1,22}=20.64, P<0.0001\right.$; Fig. 1 ; coloration of the plastron, temperature and body size were not significant and hence were removed from the final model); a similar result was found when we considered only the very first fight of each tortoise $\left(r_{23}=0.73, P<0.0001\right)$. The index of boldness was negatively associated with coloration of the plastron and temperature (multiple regression analysis: coloration: $F_{1,22}=4.80, P=0.039$; temperature: $F_{1,22}=4.02, P=0.057$; coloration of the carapace and the index of body size were not significant and hence removed from the final model). Darker eumelanic animals were bolder (Fig. 2).

\section{DISCUSSION}

In adult male eastern Hermann's tortoises, aggressiveness, boldness and activity level were significantly repeatable within individuals, but this was not the case for exploratory behaviour. In line with the proposition that coloration may be associated with behavioural traits (Ducrest et al. 2008), we found that males displaying a darker eumelanic shell were more aggressive towards conspecifics (Fig. 1) and bolder towards humans (Fig. 2).

The link between aggressiveness and melanin-based coloration has already been reported in mammals, birds, fish and reptiles (Ducrest et al. 2008), including two aquatic turtle species: in redeared slider turtles, Trachemys scripta, darker melanic males are more aggressive and dominant (Lardie 1983) and in Florida redbelly turtles, Pseudemys nelsoni, darker males initiate most aggressive confrontations (Kramer 1986). In the present study, we found that the degree of aggressiveness is correlated with the eumelanic pigmentation of the carapace. Because the carapace is the visible part of the shell, a strong dark-coloured carapace could be used to signal the expected degree of aggressiveness during male-male interactions. By manipulating the extent to which the carapace is black, we could investigate whether individuals are more prudent in front of dark rather than pale conspecifics (e.g.

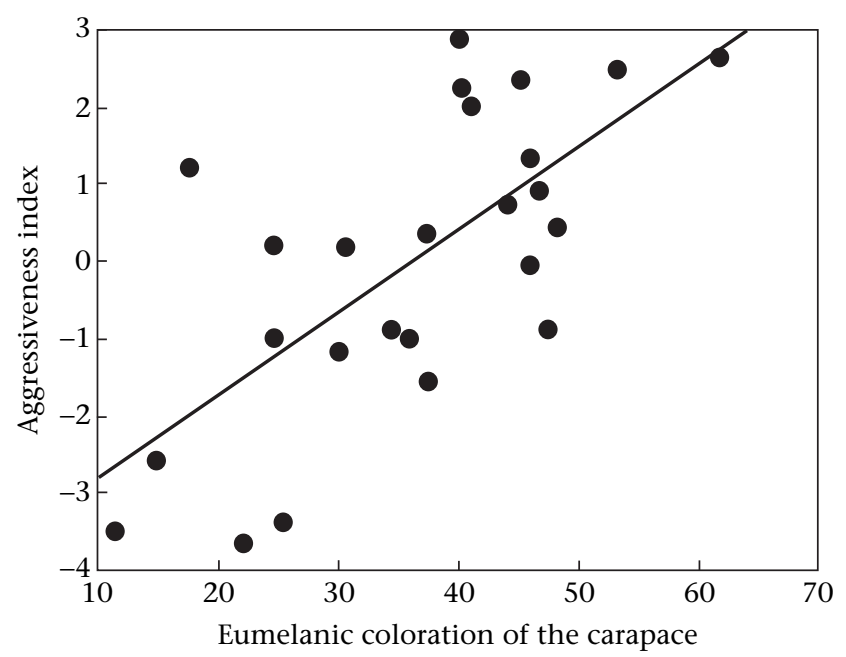

Figure 1. Relationship between the percentage of the carapace that is dark eumelanic and the index of aggressiveness in male eastern Hermann's tortoises. Pearson correlation: $r_{23}=0.69, P=0.0001$. Regression line is drawn for illustrative purposes.

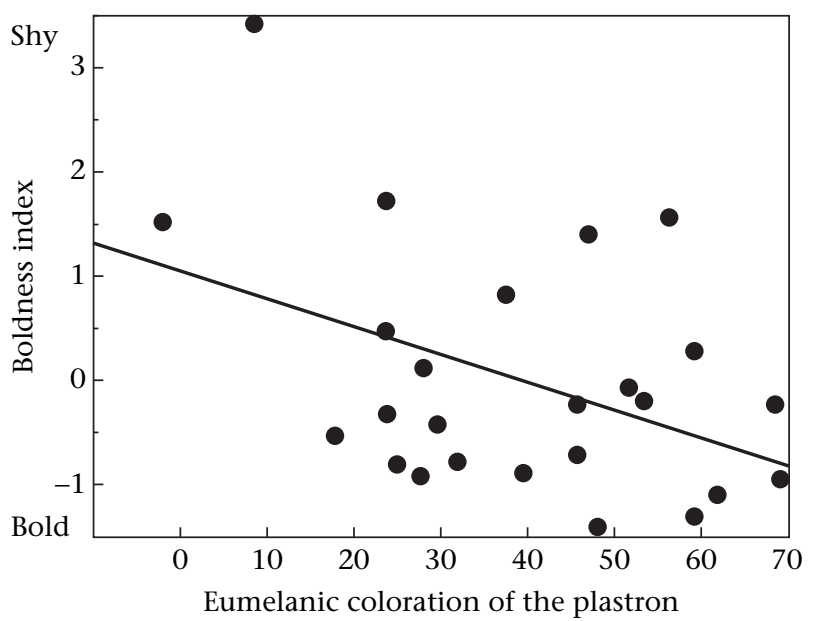

Figure 2. Relationship between the percentage of the plastron that is dark eumelanic and the index of boldness in male eastern Hermann's tortoises. Least squares from the model described in the results are presented. Pearson correlation: $r_{23}=-0.42$, $P=0.035$. Regression line is drawn for illustrative purposes.

Vercken \& Clobert 2008b). Such an experiment has been performed in the red-footed tortoise, Chelonoidis carbonaria, where dominant males have more intensively coloured spots on their head (black with red, orange, yellow or white spots) than subdominant males and in a group of tortoises with an already defined hierarchy, males with their spots painted black were attacked less by resident males (Auffenberg 1965). In our study, fearfulness towards humans was associated with coloration of the plastron but not of the carapace. From a proximate point of view, it remains unclear why this behavioural trait was correlated only with the hidden part of the shell. From an ultimate point of view, this observation suggests that melaninbased coloration may help tortoises to signal aggressiveness towards conspecifics but not boldness. Thus, the link between coloration and boldness may rather be an indirect consequence of the association between aggressiveness and coloration rather than a result of selection favouring individuals to signal boldness.

The associations between coloration and behaviour we found in eastern Hermann's tortoises could be caused by pleiotropic genes that encode for both coloration and behaviour. Given that we do not know the origins of each tortoise used in the present study, an alternative hypothesis is that dark and pale individuals originate from different geographical regions where natural selection favours different behaviours and coloration, although within populations these two phenotypic traits would not be correlated. Finally, dark tortoises may warm up more rapidly, allowing them to invest more energy in aggressive behaviour. Although we did not measure body temperature, ambient temperature did not account for aggressiveness, suggesting that temperature does not mediate the relationship between coloration, aggressiveness and boldness. Whatever the proximate mechanism underlying a link between coloration and behaviour, we still found that in captivity dark tortoises behaved differently to paler conspecifics. Our study should stimulate field studies to investigate whether within wild populations interindividual variation in coloration is also linked to behavioural patterns, raising the question of whether this association is adaptive or not.

How could colour-related behavioural tactics be maintained in natural populations? Several models have been proposed to explain the evolutionary stability of personality traits within animal populations. The interest here is to point out the specificity of each model to define the expected life history differences between dark and pale individuals. Following the model of Wolf et al. (2007), bold and shy individuals invest more in current and future reproduction, respectively. Thus, given that eumelanic coloration is associated 
with aggressiveness and boldness, this theory would predict coloration to be associated with allocation of resources to current versus future reproduction. Stamps (2007) proposed another idea to explain the maintenance of personality traits within populations. Because individuals that grow rapidly may require more food resources per unit of time, they may take more risks in foraging, implying that bold individuals may grow faster than shy conspecifics and that coloration could be correlated with growth rate (Stamps 2007). These predictions should be relatively easy to test in captivity using animals from private breeders. The key point is to investigate life history differences between differently coloured tortoises (e.g. Ducrest et al. 2008) and between tortoises showing alternative behavioural traits (Biro \& Stamps 2008). This is necessary to appraise the potential adaptive function of the link between behaviour and coloration. In this context, tortoises are appropriate because covariation between melanin-based coloration and behavioural traits is particularly strong and these animals are amenable to performing experiments and observations in captivity.

\section{Acknowledgments}

We are grateful to Jean-Marc Ducotterd (centre of Protection and Recuperation of Turtles in Chavornay, Switzerland), Serge Borcard, Vincent Hubert, Jean-Claude Repond and Esméralda Sudan for lending us their tortoises. We thank Philippe Christe, Sylvain Dubey, Andrea Pilastro, Raphaelle Flint and five anonymous referees for helpful comments on the manuscript. The study was supported by a grant of the Swiss National Science Foundation (31003A_120517 to A.R) and, in part, by a Japan Society for the Promotion of Sciences (JSPS) grant to K.W. (No. 21500358).

\section{References}

Abramoff, M. D., Magelhaes, P. J. \& Ram, S. J. 2004. Image processing with ImageJ Biophotonics International, 11, 36-42.

Auffenberg, W. 1965. Sex and species discrimination in two sympatric South American tortoises. Copeia, 1965, 335-342.
Biro, P. A. \& Stamps, J. A. 2008. Are animal personality traits linked to life-history productivity? Trends in Ecology \& Evolution, 23, 361-368.

Cooper, W. E. Jr. \& Greenberg, N. 1992. Reptilian coloration and behaviour. In: Biology of the Reptilia, Hormones, Brain, and Behavior (Ed. by C. Gans \& D. Crews), pp. 298-422. Chicago: University of Chicago Press.

Ducrest, A-L., Keller, L. \& Roulin, A. 2008. Pleiotropy in the melanocortin system, colouration and behavioural syndromes. Trends in Ecology \& Evolution, 23, $502-510$.

Jawor, J. M. \& Breitwisch, R. 2003. Melanin ornaments, honesty, and sexual selection. Auk, 120, 249-265.

Kramer, M. 1986. Field studies on a freshwater Florida turtle, Pseudemys nelsoni. In: Behavioral Ecology and Population Biology (Ed. by L. C. Drickamer), pp. 29-34. Toulouse: Privat, I.E.C.

Lapparent de Broin, F., Bour, R., Parham, J. F. \& Perälä, J. 2006. Eurotestudo, a new genus for the species Testudo hermanni Gmelin, 1789 (Chelonii, Taestudinidae). Comptes Rendus Palevol, 5, 803-811.

Lardie, R. L. 1983. Aggressive interactions among melanistic males of the red-eared slider, Pseudemys scripta elegans (Wied). Bulletin of the Oklahoma Herpetological Society, 8, 105-117.

Lessells, C. M. \& Boag, P. T. 1987. Unrepeatable repeatabilities: a common mistake. $A u k, 104,116-121$

Porter, W. P. \& Norris, K. S. 1969. Lizard reflectivity change and its effect on light transmission through body wall. Science, 163, 482-484.

Sall, J. \& Lehman, A. 1996. JMP Start Statistics: A Guide to Statistical and Data Analysis using JMP and LMP in Software. 4th edn. London: Duxbury Press.

Schilliger, L. 2007. Les Tortues 'de Jardin'. Guide des Soins E' des Maladies. Mouleydier: Animalia Editions.

Sih, A., Bell, A. M., Johnson, J. C. \& Ziemba, R. E. 2004. Behavioural syndromes: an integrative overview. Quarterly Review of Biology, 79, 242-277.

Stamps, J. A. 2007. Growth-mortality tradeoffs and 'personality traits' in animals. Ecology Letters, 10, 355-363.

Trullas, S. C., van Wyk, J. H. \& Spotila, J. R. 2007. Thermal melanism in ectotherms. Journal of Thermal Biology, 32, 235-245.

Ventura, D. F, Zana, Y, De Souza, J. M. \& Devoe, R. D. 2001. Ultraviolet colour opponency in the turtle retina. Journal of Experimental Biology, 204, 2527-2534.

Vercken, E. \& Clobert, J. 2008a. Ventral colour polymorphism correlates with alternative behavioural patterns in female common lizards (Lacerta vivipara). Ecoscience, 15, 320-326.

Vercken, E. \& Clobert, J. 2008b. The role of colour polymorphism in social encounters among female common lizards. Herpetological Journal, 18, $223-230$.

Vetter, H. 2006. Tortue d'Hermann, Tortue de Boettger et Tortue d'Herzégovie, Testudo Boettgeri, Hercegovinensis et Hermanni. Frankfurt am Main: Editions Chimaria.

Willemsen, R. E. \& Hailey, A. 1999. A latitudinal cline of dark plastral pigmentation in the tortoise Testudo hermanni in Greece. Herpetological Journal, 9, 125-132.

Wolf, M., van Doorn, G. S., Leimar, O. \& Weissing, F. J. 2007. Life-history trade-offs favour the evolution of animal personalities. Nature, 447, 581-584. 